RASĀYAN J. Chem.

Vol. 13 | No. 3 |1313-1320| July - September | 2020 ISSN: 0974-1496 | e-ISSN: 0976-0083 | CODEN: RJCABP

\title{
ATENOLOL IMPRINTED POLYMER WITH BUTANOL AS A POROGENIC SOLVENT: USING TWO POLYMERIZATION METHODS
}

\author{
A. N.Hasanah*, J. Tristi and D. Rahayu \\ Pharmaceutical Analysis and Medicinal Chemistry Department, Faculty of Pharmacy, \\ Universitas Padjadjaran, Jalan Raya Bandung Sumedang Km 21 Jatinangor, West Java, \\ Indonesia, Postal Code 45363 \\ *E-mail: Aliya.n.hasanah@unpad.ac.id
}

\begin{abstract}
Atenolol is a beta-blocker drug that has the effect of reducing the heart rate and blood pressure in the body and is usually misused by athletes for doping. Detection of atenolol in biological fluid needs sample preparation that carefully selects atenolol. A method that can separate selectively is Molecularly Imprinted Polymer (MIP). The purpose of this research is to find out the performance of the polymer and also characterize it. This study was carried out in several stages included calculation of the association constants, and the synthesis of atenolol MIP sorbent using two methods with atenolol, methyl methacrylate and butanol as a template, monomer and porogen consecutively. After polymer synthesized the template was extracted from it and tested for its adsorption, capacity, and selectivity. The polymer's characterizations showed the absence of a vinyl group at wavenumbers of 900$1000 \mathrm{~cm}^{-1}$ in the FTIR spectrum of both sorbents. The imprinting factor of the polymer produced by precipitation polymerization reached 5.967 which is similar to compounds with an adsorption capacity of $2.1661 \mathrm{mg} / \mathrm{g}$ of the sorbent. A molecularly imprinted polymer (MIP) atenolol sorbent that is synthesized with methyl methacrylate as the functional monomer in butanol has the potential to be used as an MI-SPE sorbent.
\end{abstract}

Keywords: Atenolol, Molecular Imprinting Polymer, Solid-phase Extraction, Methyl Methacrylate, Butanol

(C) RASĀYAN. All rights reserved

\section{INTRODUCTION}

Atenolol is a specific antagonist of $\beta 1$-adrenoreceptor that blocks the activation of sympathetic to the heart, reducing heart rate, and also cardiac contractility, the output of the cardiac and blood pressure. ${ }^{1}$ These effects prompt some athletes to misuse atenolol for doping in some sports competitions where tachycardia can be detrimental to their achievement. ${ }^{2}$ Therefore, it is essential to monitor doping in athletes by analyzing the presence of atenolol in their biological fluids.

Solid-phase extraction (SPE) is one of the extraction methods that can be used for the analysis of drugs if it is combined with high-performance liquid chromatography (HPLC). ${ }^{3}$ The solid phase in SPE can separate the analyte using different interactions between the sorbent and other components in the sample. However, their interactions are not specific. ${ }^{4}$ Also, the small amount of analyte in the biological sample means that the SPE needs to be selective and sensitive. Currently, molecularly imprinted polymers are developed and used as sorbents in SPE to improve its selectivity and sensitivity. Molecularly imprinting polymers is a technique that designs artificial receptors in the polymer and it has selectivity and also specificity against given analyte, which makes them ideal for using in extraction methods. ${ }^{5}$

This study uses two polymerization methods: bulk and precipitation polymerization. Bulk polymerization was a primary synthesis method to synthesize MIP. ${ }^{6}$ This method is the most popular since it is simple and uses a small amount of solvent. Nevertheless, when we used bulk as a method we need to crush, grind and sieve the imprinted polymer for having rightful particle size and it caused nonuniform size. ${ }^{7}$ Precipitation polymerization uses more solvent than bulk polymerization. This method concedes the formation of microsphere beads. The polymer in precipitation method will grow and precipitate only

Rasayan J. Chem., 13(3), 1313-1320(2020)

http://dx.doi.org/10.31788/RJC.2020.1335765

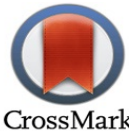


RASĀYAN J. Chem.

Vol. 13 | No. 3 |1313-1320| July - September | 2020

when the size is large enough to make it insoluble in the mixture. This method is easy and less tedious than bulk polymerization and a good yield of uniform beads. ${ }^{5}$

Currently, a molecularly imprinted polymer for atenolol has never been synthesized using butanol as a porogen in methyl methacrylate monomer. Other researchers have done research on molecularly imprinted solid-phase extraction (MI-SPE) to extract atenolol, ${ }^{8-10}$ but they never used precipitation polymerization as we did in this research, and the imprinting factors (IF) were around one. Methyl methacrylate can act as a hydrogen bond acceptor and give it to template for having hydrogen bond that needed in noncovalent polymerization method.

This research will compare two methods of polymerization to have the molecularly imprinted polymer (MIP) for atenolol, using butanol as a porogen with methyl methacrylate monomer. The MIP will be synthesized and characterized against a standard solution of atenolol and its analog.

\section{EXPERIMENTAL}

\section{Material and Methods}

Atenolol $\left(\mathrm{C}_{14} \mathrm{H}_{22} \mathrm{~N}_{2} \mathrm{O}_{3}\right)$, metoprolol tartrate $\left(\mathrm{C}_{34} \mathrm{H}_{56} \mathrm{~N}_{2} \mathrm{O}_{12}\right)$, and propranolol hydrochloride $\left(\mathrm{C}_{16} \mathrm{H}_{22} \mathrm{ClNO}_{2}\right)$ were acquired from Tokyo Chemical Industry (TCI). Methyl methacrylate $\left(\mathrm{C}_{5} \mathrm{H}_{8} \mathrm{O}_{2}\right)$ (MMA) was acquired from Sigma Aldrich and was purified with aluminium chloride before being used, ethylene glycol di-methacrylate $\left(\mathrm{C}_{10} \mathrm{H}_{14} \mathrm{O}_{4}\right)$ (EGDMA) was also purchased from Sigma Aldrich. Benzoyl peroxide $\left(\mathrm{C}_{14} \mathrm{H}_{10} \mathrm{O}_{4}\right)$ (BPO), butanol $\left(\mathrm{C}_{4} \mathrm{H}_{9} \mathrm{OH}\right)$, acetic acid $\left(\mathrm{CH}_{3} \mathrm{COOH}\right)$, acetonitrile $\left(\mathrm{CH}_{3} \mathrm{CN}\right)$, and methanol $\left(\mathrm{CH}_{3} \mathrm{OH}\right)$ HPLC grade were purchased from Merck. All the chemicals that were used were available in the market in analytical grade, if not specified.

A Spectrophotometer (Specord 200 from Analytic Jena), a water bath shaker from Memmert, an infrared spectrophotometer (Shimadzu Prestige 21), a Hitachi TM 3000 as the scanning electron microscope, a metal sieve (60 mesh), and an ultrasonicator bath were used.

Methods that will be used in this experiment are bulk and precipitation polymerization using butanol as a porogenic solvent.

\section{Determining the Template-functional Monomer Interaction}

A stock solution of atenolol $\left(2 \times 10^{-5} \mathrm{M}\right)$ and methyl methacrylate as the functional monomer $\left(1 \times 10^{-2} \mathrm{M}\right)$ was prepared in butanol. The atenolol absorbance was recorded using a spectrophotometer, and then MMA as the functional monomer was added in increments. The binding constant was estimated using the Benesi-Hildebrand equation. ${ }^{11}$

\section{Synthesis of Molecularly Imprinted Polymer}

Bulk polymerization was carried out using atenolol as a template $(0.2663 \mathrm{~g})$, MMA as a functional monomer $(400 \mu \mathrm{L})$, EGDMA as the crosslinker $(3.77 \mathrm{~mL})$, and BPO as the initiator $(750 \mathrm{mg})$. All of these were dissolved in $10 \mathrm{~mL}$ of porogen solvent in a tube. The mixture was then sonicated for 20 minutes. The tube was sealed and heated at $70^{\circ} \mathrm{C}$ in the oven for two hours. The mixture was then incubated in a water bath at $70^{\circ} \mathrm{C}$ for 22 hours. The rigid polymers produced were then ground, filtered using a metal sieve (60 mesh), wet-sieved using acetone, and then washed using methanol. Atenolol as a template was extracted from the particles, using a $200 \mathrm{~mL}$ mixture of methanol and acetic acid (v/v9:1) in the Soxhlet apparatus for 24 hours, and then preserved for 18 hours in an oven at $50^{\circ} \mathrm{C}$. To ensure all atenolol has been extracted UV Visible spectrophotometer was used to measure the absorbance of the filtrate. Non-imprinted polymers (NIPs) were prepped using the same method for the MIPs without the addition of the template in the polymerization. ${ }^{11,12}$

Precipitation polymerization was carried out using atenolol as a template $(0.2663 \mathrm{~g})$ and it was dissolved in butanol $(50 \mathrm{~mL})$ in the bottle. The mixture then was sonicated for five minutes. The functional monomer, MMA $(400 \mu \mathrm{L})$, and butanol $(300 \mathrm{~mL})$ were added to the mixture and sonicated. The crosslinker, EGDMA $(3.77 \mathrm{~mL})$ and BPO $(750 \mathrm{mg})$ as initiator was added consecutively. All mixtures were sonicated until entirely dissolved. The bottle was then sealed, heated at $70^{\circ} \mathrm{C}$ in the oven for two hours, and incubated in a water bath shaker for 22 hours at $70^{\circ} \mathrm{C}$ until polymers were formed. The polymers that were produced were extracted using the procedure from Hasanah et al. ${ }^{13}$ 
RASĀYAN J. Chem.

Vol. 13 | No. 3 |1313-1320| July - September | 2020

\section{Rebinding and Isotherm Adsorption Studies using the Batch Method}

The rebinding method was performed in butanol for the bulk polymerization method and a methanolacetonitrile mix for the precipitation polymerization. This procedure was carried done by incubating 20 $\mathrm{mg}$ of mip/nip in a $5 \mathrm{~mL}$ volume of the atenolol solution in different concentrations $(2.5,5,7.5$, and 10 $\mathrm{ppm}$ ), in a vial for three hours using agitator apparatus. The amount of atenolol in the filtrate was analyzed using a spectrophotometer. The graph between bound atenolol and free atenolol was made to calculate adsorption capacity. ${ }^{13}$

\section{Adsorption Study toward Similar Compounds}

The selectivity of the polymer was analyzed using atenolol, metoprolol, and propranolol solutions (5 $\mathrm{ppm}$ ). In the vial, $20 \mathrm{mg}$ of MIP/NIP was added into a solution of atenolol, metoprolol, and propranolol and incubated for three hours using agitator apparatus. The amount of analyte in the filtrate was then analyzed using a UV-visible spectrophotometer (Specord 200 Analytic Jena). The coefficient of distribution $\left(\mathrm{K}_{\mathrm{D}}\right)$ and imprinting factor (IF) were then calculated using the equation from Liu et al. ${ }^{14}$ All the data analysis was done using Excel.

\section{Testing the Polymers' Physical Characteristics Using Infrared Spectroscopy (FTIR) and Scanning Electron Microscopy (SEM)}

The infrared spectrum of MIP/NIP was obtained using FTIR (Shimadzu Prestige-21). This procedure was carried out on polymer samples, before and after extraction, using a Soxhlet apparatus. SEM characterization was used for analyzing the differences in the morphology of MIP and NIP. ${ }^{13}$

\section{Determining the Template-functional Monomer Interaction}

Interaction between the template and functional monomer is determined by the UV titration method. The result from UV was interpolated on a graph within $1 /[\mathrm{G}]$ and $1 / \Delta \mathrm{Y}$. The resulting linear equation from the graph was as follows: $y=0.0011 \mathrm{x}+0.1724$. The association constant was computed from the BenesiHildebrand equation. A value of $6.58 \times 10^{2} \mathrm{M}^{-1} \mathrm{~s}$ was obtained from the calculation.

The determined association constant $(\mathrm{Ka})$ was analyzed to understand the interaction and affinity within the template (atenolol) and monomer (MMA). The Ka value from the calculation showed that there is an interaction among them. The synthesis of the polymer in this research was done by using two methods of polymerization: precipitation and bulk polymerization. This experiment aims to compare the chemical and physical characteristics of both methods. Butanol is used as the porogen solvent, because for a polymer that has a noncovalent interaction, a less polar or nonpolar solvent gives better imprinting efficiency than a polar one. The polar solvent can interrupt the hydrogen interaction between the template and the monomer. ${ }^{15}$ Figure-1 shows the proposed binding scheme within the template (atenolol) and monomer (MMA).

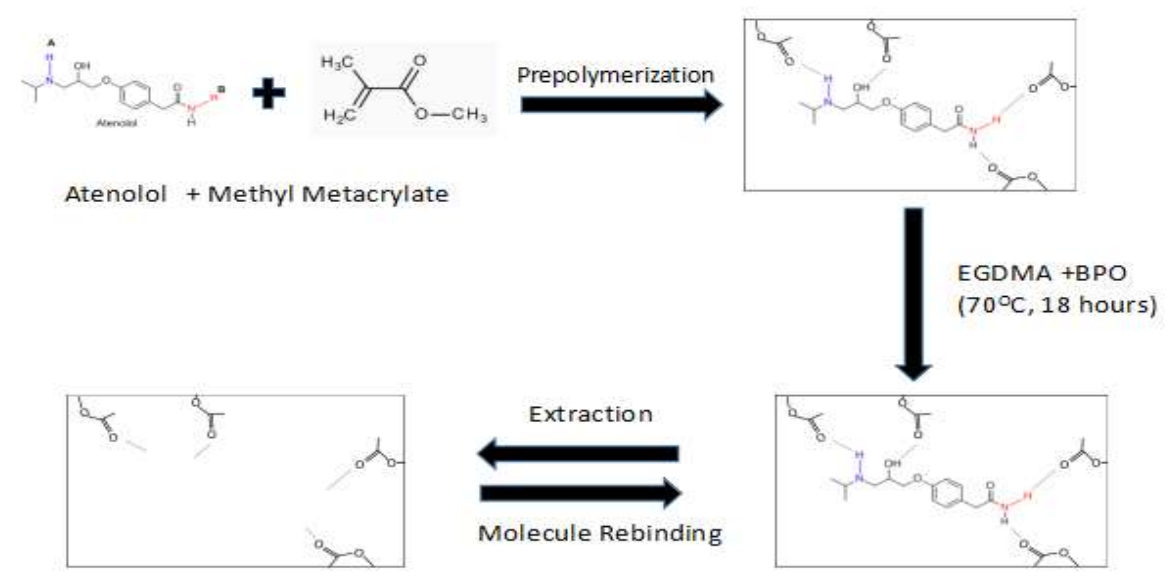

Fig.-1: Proposed Binding Scheme within the Template (Atenolol) and Monomer (MMA) 
RASĀYAN J. Chem.

Vol. 13 | No. 3 |1313-1320| July - September | 2020

The extraction using the Soxhlet apparatus aims to eliminate the template (atenolol) from the polymer and produce pores on the imprinted polymer. These pores are used as the binding site for the target compounds and polymers. The solvent that is used for this extraction is a mixture of methanol and acetic acid ( $\mathrm{v} / \mathrm{v}$ 9:1). Acetic acid was added to the solvent extraction as a modifier for increasing extraction efficiency because the acidic compound can help the solvent reach the polymer's pores ${ }^{16}$ and disturb the hydrogen interaction among the template and the monomer. ${ }^{17}$

\section{Rebinding and Isotherm Adsorption Studies Using the Batch Method}

Binding capacity and selectivity of the polymer can be evaluated using batch rebinding. ${ }^{18}$ Usually, for noncovalent binding a Scatchard plot will have two straight lines, illustrating a heterogenous affinity on the binding site of the polymer. ${ }^{19}$ Batch rebinding and isotherm adsorption studies were done to find out how many analytes can be adsorbed by the sorbent. The results of the adsorption capacity were depicted in Table-1 and Table-2 using the Langmuir and Freundlich isotherms.

Table-1: Results From the Calculation of Adsorption Capacity Using the Langmuir Isotherm ( $\mathrm{n}=3$ ).

\begin{tabular}{c|c|c|c}
\hline Polymer & $\mathrm{b}(\mathrm{mg} / \mathrm{g})$ & $\mathrm{K}(\mathrm{L} / \mathrm{mg})$ & $\mathrm{r}^{2}$ \\
\hline NIP Bulk Polymerization & 0.058 & 1.301 & 0.999 \\
\hline MIP Bulk Polymerization & \multicolumn{3}{|c}{ Undetermined } \\
\hline NIP Precipitation Polymerization & 0.126 & 0.009 & 0.817 \\
\hline MIP Precipitation Polymerization & 0.073 & 0.625 & 0.212 \\
\hline
\end{tabular}

Table-2: Results From the Calculation of the Adsorption Capacity using the Freundlich Isotherm ( $\mathrm{n}=3$ ).

\begin{tabular}{c|c|c|c}
\hline Polymer & $\mathrm{m}(\mathrm{mg} / \mathrm{g})$ & $\mathrm{a}(\mathrm{L} / \mathrm{mg})$ & $\mathrm{r}^{2}$ \\
\hline NIP Bulk Polymerization & 0.754 & 5.683 & 0.796 \\
\hline MIP Bulk Polymerization & \multicolumn{3}{|c}{ Undetermined } \\
\hline NIP Precipitation Polymerization & 0.080 & 1.534 & 0.005 \\
\hline MIP Precipitation Polymerization & 2.166 & 18.126 & 0.807 \\
\hline
\end{tabular}

Adsorption capacity is the maximum amount of substances that can be adsorbed by the polymers. ${ }^{20,21}$ The Langmuir isotherm (Table-1) is chosen because the correlation coefficient from the experiment is better than the result produced by the Freundlich isotherm (Table-2), so it can be concluded that the polymers adhere to the Langmuir isotherm. From Table-1, the maximum adsorption capacity of the adsorbent produced by bulk polymerization cannot be compared because the capacity of imprinted polymers cannot be determined. A possible explanation for this is that in this condition the polymers form a monolayermultilayer formation that could be determined using the BET (Brunauer- Emmett- Teller) isotherm.

The imprinted polymer has higher than the non-imprinted (NP) one because the imprinted polymer (IP) has a stronger affinity with a template compared to NP. This happens because the imprinted polymers have a complementary and specific binding site with the atenolol molecule. ${ }^{22}$ In the polymer matrices with a template in them, there are intermolecular interactions, such as hydrogen, or dipole-dipole, or ionic interactions between template molecules and monomers. This causes the polymer to recognize a functional group of specific compounds. ${ }^{5}$

This experiment shows that the better polymer size and conditions obtained from precipitation polymerization do not always provide better adsorption results when compared with bulk polymerization. This could be because the estimated total pore volume for imprinted polymers produced by precipitation polymerization is lower than that for polymers from bulk polymerization. Also, higher particle porosity in polymers can affect the performance of the extraction. ${ }^{23}$

Adsorption Study toward Similar Compounds

To verify the adsorption of imprinted polymers for the template molecules, the bond is tested against atenolol and its analogs. ${ }^{24}$ Metoprolol and propranolol are used in the test because they are in the same 
RASĀYAN J. Chem.

Vol. 13 | No. 3 |1313-1320| July - September | 2020

group as atenolol (beta-blocker). These compounds are similar to those in the hydroxylamine group, with a secondary amine functional group or $\mathrm{N}$-isopropylamine. Nevertheless, the three of them have a different aromatic ring in the structure. ${ }^{25}$ The molecular size of atenolol is $266.341 \mathrm{~g} / \mathrm{mol}$, metoprolol is 267.369 $\mathrm{g} / \mathrm{mol}$, and propranolol is $259.349 \mathrm{~g} / \mathrm{mol}^{25}$ Figure-2 shows the structure of atenolol, metoprolol and propranolol.

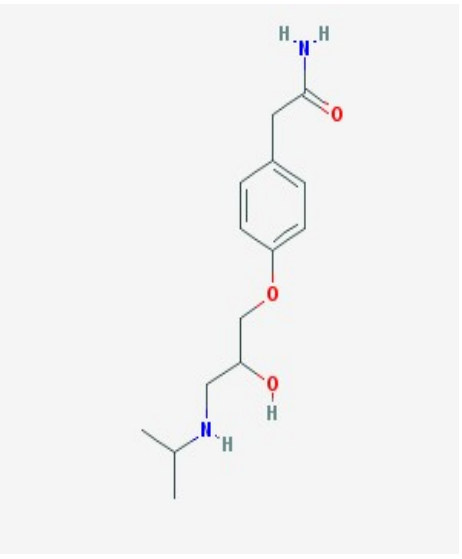

(a)

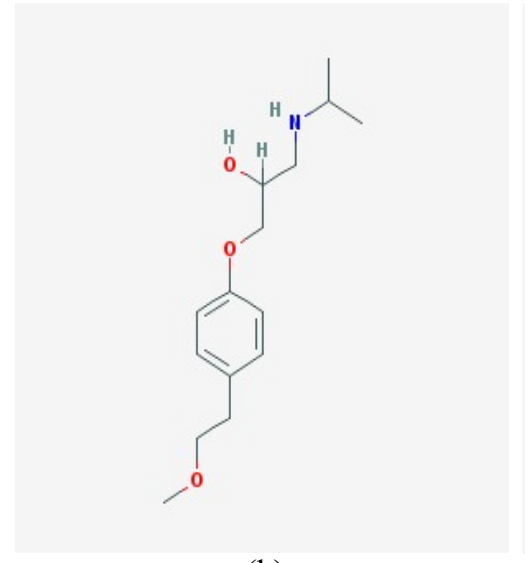

(b)

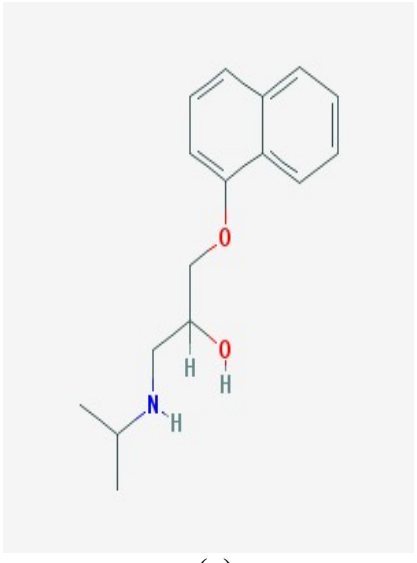

(c)

Fig.-2: Structures of (a) Atenolol (b) Metoprolol (c) Propranolol ${ }^{25}$

The $K_{D}$ value indicates how many analytes can bind with a sorbent. ${ }^{26}$ The higher the $K_{D}$ value, the more analyte that can be adsorbed with the sorbent. The IF value can be obtained by comparing the $\mathrm{K}_{\mathrm{D}}$ values for MIPs and NIPs. If the IF value is more than one, it shows that imprinted polymers have a better ability to adsorb the analyte compared with a non-imprinted polymer. The IF values for polymers produced by bulk polymerization cannot be calculated because the imprinted polymer has infinity adsorption, but it can be concluded that the imprinted polymer can adsorb analyte very well. From Table-3, the IF values produced by precipitation polymerization from atenolol are higher than those from propranolol and metoprolol. This shows that the produced sorbent can distinguish compounds that are similar to atenolol. This means the imprinted polymers have a good selectivity. Another researcher has done research on MISPE for atenolol ${ }^{8-10}$ using bulk polymerization, and the imprinting factor (IF) was around one. Their IF value is lower than our result.

Table-3: The Adsorption Study toward Similar Structures; Results From the Imprinted and Non-imprinted Polymers produced by Bulk and Precipitation Polymerization

\begin{tabular}{c|c|c|c|c}
\hline \multirow{2}{*}{ Polymer } & & \multicolumn{2}{|c|}{$\mathrm{K}_{\mathrm{D}}$} & \multirow{2}{*}{ IF } \\
\cline { 3 - 5 } & & $\mathrm{MIP}$ & $\mathrm{NIP}$ & \\
\hline \multirow{3}{*}{ Bulk polymerization } & Atenolol & Infinity & 22.727 & - \\
\cline { 2 - 5 } & Propanolol & 12.097 & 72.421 & 0.167 \\
\cline { 2 - 5 } & Metoprolol & 118.063 & 126.452 & 0.934 \\
\hline \multirow{2}{*}{$\begin{array}{c}\text { Precipitation } \\
\text { polymerization }\end{array}$} & Atenolol & 62.309 & 10.443 & 5.967 \\
\cline { 2 - 5 } & Propanolol & 4.902 & 56.604 & 0.087 \\
\cline { 2 - 5 } & Metoprolol & 103.535 & -21.953 & 4.716 \\
\hline
\end{tabular}

Testing the Polymer's Physical Characteristics using Infrared Spectroscopy (FTIR) and Scanning Electron Microscopy (SEM)

FTIR was performed on the imprinted and non-imprinted polymers, before and after extraction, using a Soxhlet apparatus to differentiate between the functional group in each polymer. The polymer functional group results from the FTIR was depicted in Fig.-3 and Fig.-4. 
RASĀYAN J. Chem.

Vol. 13 | No. 3 |1313-1320| July - September | 2020

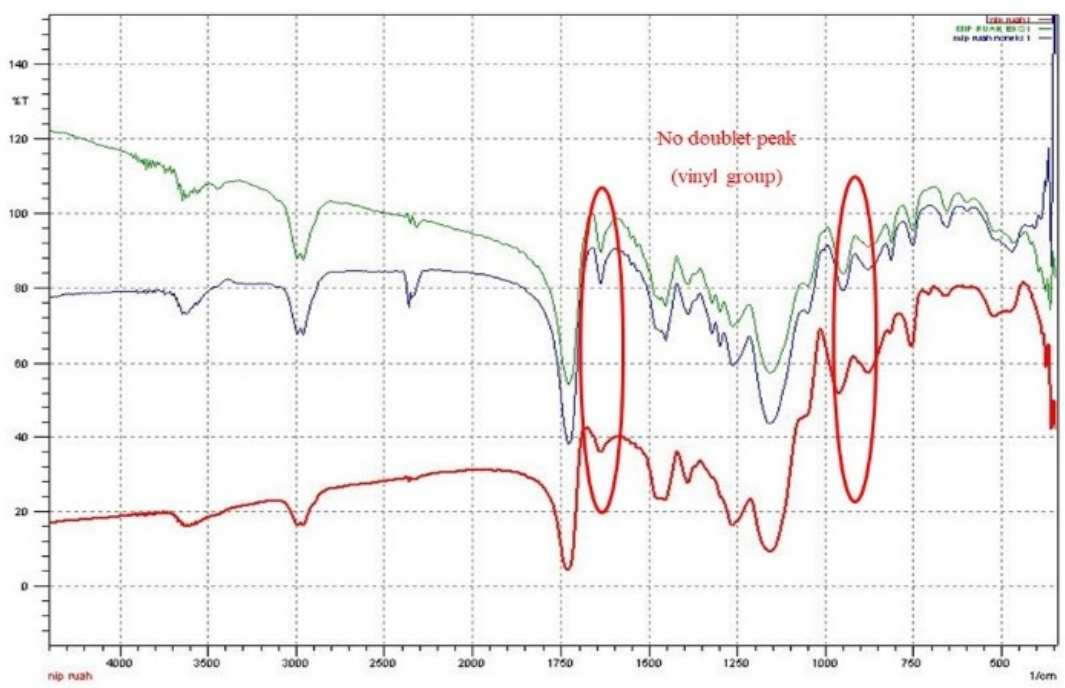

Fig.-3: The Result of FTIR Spectrum Polymers produced by Bulk Polymerization (Red: NIP, Green: MIP before Template Extraction, Blue: MIP after Template Extraction)

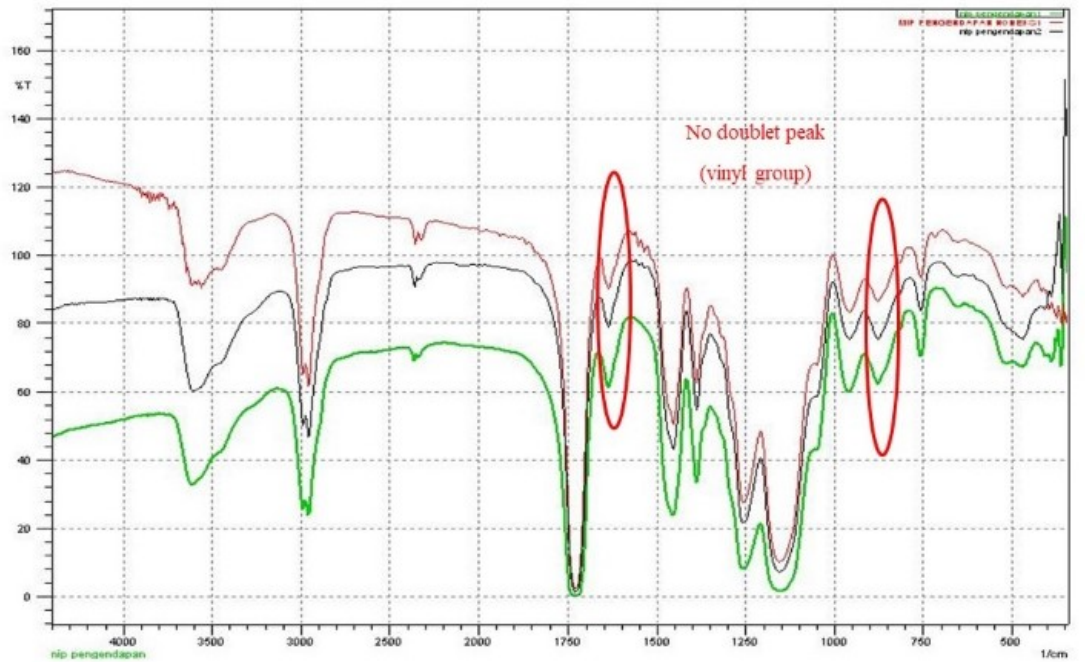

Fig.-4: The Result of FTIR Spectrum Polymers produced by Precipitation Polymerization (Red : NIP, Green: MIP before Extraction of the Template, Black: MIP after Extraction of the Template)

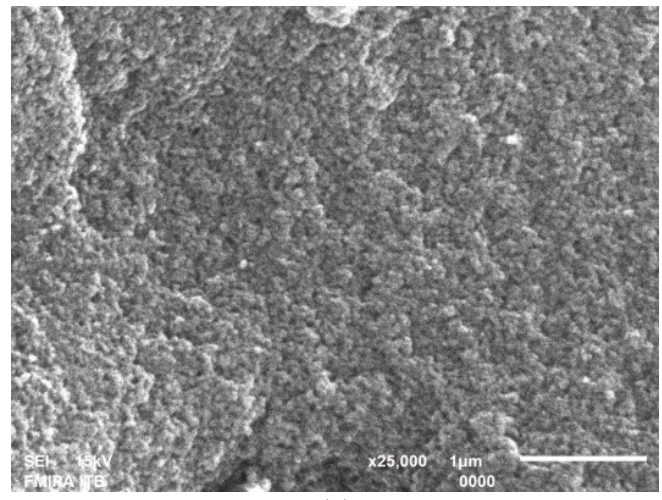

(a)

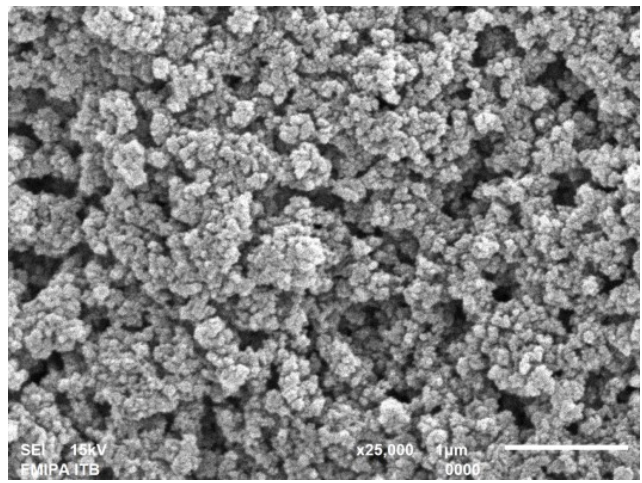

(b)

Fig.-5: SEM Result of (a) Imprinted Polymer (b) Nonimprinted Polymer produced by Bulk Polymerization 
FTIR spectroscopy is advantageous in monitoring changes in the removal of a functional group from the imprinted polymers. From Fig.-3 and Fig.-4, the FTIR spectrum from both polymerizations does not have a vinyl group, in the form of a double peak in wave number $900-1000 \mathrm{~cm}^{-1}$. A vinyl group can be used as an indicator of the level of perfection of the reaction in the polymerization process. ${ }^{27}$ The absence of this group suggests that the polymerization reaction ran perfectly. ${ }^{28}$

The polymer that is used for SEM characterization is the polymer produced by bulk polymerization because an evaluation of the results shows that the sorbent has better adsorption capacity and selectivity than the polymer produced by precipitation polymerization. In Fig.-5, the imprinted polymer has smaller pores so it can bind the analyte more specifically. Also, the smaller pores can increase the surface area which means the polymer can bind with more analyte compared with a non-imprinted polymer. ${ }^{29,30}$

The surface morphology and particle size of the MIPs and NIPs were analyzed using SEM. The SEM result of the best polymer, which is the polymer produced by bulk polymerization, can be seen in Fig.-5.

\section{CONCLUSION}

MIP for atenolol sorbent synthesized in butanol using methyl methacrylate as the functional monomer has the potential to be used as a sorbent in MI-SPE.

\section{ACKNOWLEDGMENT}

The Ministry of Research, Technology and the Higher Education Republic of Indonesia for funding this research trough Penelitian Terapan Unggulan Perguruan Tinggi (PTUPT) 2018.

\section{REFERENCES}

1. G. L. Bakris, Journal of Cardiovascular Pharmacology, 53, 5(2009), DOI: 10.1097/FJC.0b013e31819fd501.

2. P. Gupta, R. N. Goyal, Journal of The Electrochemical Society., 163, 13(2016), DOI: 10.1039/C4RA13777A.

3. L. X. Yi., R. Fang, G. H. Chen, Journal of Chromatography Sciences, 51, 7(2013), DOI: 10.1093/chromsci/bmt024.

4. G. Vasapallo, R. Del Sole, L. Mergola, M. R. Lazzoi, A. Scardino, S. Scorrano, Internartional Journal of Molecular Science.,12, 9 (2011), DOI:10.3390/ijms12095908.

5. A.N. Hasanah, S. Suryana, M. Mutakin, D. Rahayu, Asian Journal of Chemistry, 29, 11(2017), DOI: 10.14233/ajchem.2017.20728.

6. A. Poma, A.P.F. Turner, S.A. Piletsky, Trends in Biotechnology, 28,12(2010), DOI: 10.1016/j.tibtech.2010.08.006.

7. P. Thordarson, Chemical Society Reviews., 40, 3(2011), DOI: 10.1039/C0CS00062K.

8. A.E. Bodoki, B.C. Iacob, L.E. Gliga, S. Oprean, D. Spivak, A.N. Gariano, E. Bodoki, Molecules, 23, 8 (2018), DOI:10.3390/molecules23081875.

9. T. Alizadeh, Journal of Separation Sciences, 37, 14 (2014), DOI: 10.1002/jssc. 201400088.

10. Y. Gorbani, H. Yilmaz, H. Basan, Luminescence, 32, 8(2017), DOI:10.1002/bio.3335.

11. T. Nurhayati, Yanti, I. Royani, Widayani, Khairurrijal, Journal of Physics Conference series, 739, 1(2016), DOI:10.1088/1742-6596/739/1/012127.

12. S. Anasari, G. Azam, Journal of Chemical Health Risk, 7, 3(2017), DOI: 10.22034/JCHR.2017.544184.

13. A. N. Hasanah, E. K. Rahmana, I. Slamet, Journal of Applied Sciences, 15(11), 1288(2015), DOI: $10.3923 /$ jas.2015.1288.1296.

14. P. Liu, L. Liu, L. Zhang, N. Jiang, Z. Liu, Y. Wang, Frontier in. Chemistry, 3, 4(2008), DOI: $10.1002 /$ jssc. 201701014.

15. L. Chen, X. Wang, W. Lu, X. Wu, J. Li, Chemical Society Review, 45, 8(2016), DOI: 10.1039/C6CS00061D.

16. P.J. Wu, J. Yang, Q.D. Su, Y. Gao, X.L. Zhu, J.B. Cai, Chinese Journal of Analytical Chemistry, 35, 4 (2007), DOI:10.9734/IRJPAC/2018/38586. 
RASĀYAN J. Chem.

Vol. 13 | No. 3 |1313-1320| July - September | 2020

17. F. Omidi, M. Behbahni, A. S. Abandansari, A. Sedighi, S. Shahtaher, Journal of Environmental Health Science., 12, 1(2014), DOI:10.1186/s40201-014-0137-z.

18. J. Haginaka, Journal of Chromatography B., 866, 1(2008), DOI:10.1016/j.jchromb.2007.07.019.

19. L. Longo, S. Scorrano, G. Vasapollo, Journal of Polymer Research., 17, 5(2010), DOI: 10.1007/s10965-009-9356-X.

20. Z. Dorkó, A. Sakolczai, T. Verbic, G. Horvai, Journal of Separation Science., 38, 24(2015), DOI: $10.1002 /$ jssc. 201500874.

21. D.M. Levan, T. Vermeulen, Journal of Physical Chemistry, 85, 22(1981), DOI: 10.1021/j150622a009.

22. T.V. Nicolescu, A. Sarbu, S.O. Dima, C. Nicolae, D. Donescu, Journal of Applied Polymer Science.,127, 1(2012), DOI: 10.1002/app.37528.

23. S. Wei, A. Molinelli, B. Mizaikoff, Biosensosr and Bioelectronics., 21,10 1943(2006), DOI: 10.1016/j.bios.2005.09.017.

24. J.Y. Yu, X.L. Hu, R.Y. Song, S. Xi, Advance Material Research, 148(2010), DOI: 10.1002/app.22519.

25. L. Komsta, M. Wakmundzka-Hajnos, J. Sherma, 2013, Thin Layer Chromatography in Drug Analysis., CRC Press, Boca Raton, pp. 25-35.

26. R. J. Ansel, Advances in Biochemical Engineering/Biotechnology, 150, Springer, Cham (2015), DOI: 10.1007/10_2015_316.

27. J. B. Lambert, S. Gronert, H. F. Shurvell, D. Lightner, R.G. Cooks, 1998, Organic structural Spectroscopy, Prentice Hall, New Jersey, pp. 188.

28. G.Li, T. Wang,, M.F. Huang, T.M. Gao, X. Fu, Journal of Applied Polymer Science,132, 17(2015), DOI: $10.1002 /$ app.41899.

29. P. Sikiti, T.A.M. Msagati, B.B. Mamba, A.K. Mishra, Journal of Environmental Health Science., 12, 82 (2014), DOI:10.1186/2052-336X-12-82.

30. A. N. Hasanah, M. Suherman, I. Susanti, I. Pitaloka, R. Mustarichie, Rasayan Journal of Chemistry, 12, 3(2019), DOI:10.31788/RJC.2019.1235202

[RJC-5765/2020] 